\title{
Using Design Fiction To Reflect on Autonomy in Smart Technology For People Living With Dementia
}

Britta F. Schulte

University College London

London, UK

Britta.schulte.15@ucl.ac.uk
Permission to make digital or hard copies of all or part of this work for personal or classroom use is granted without fee provided that copies are not made or distributed for profit or commercial advantage and that copies bear this notice and the full citation on the first page. Copyrights for components of this work owned by others than the author(s) must be honored. Abstracting with credit is permitted. To copy otherwise, or republish, to post on servers or to redistribute to lists, requires prior specific permission and/or a fee. Request permissions from Permissions@acm.org.

Ubicomp/ISWC'16 Adjunct, September 12 - 16, 2016, Heidelberg, Germany

Copyright is held by the owner/author(s). Publication rights licensed to ACM.

ACM 978-1-4503-4462-3/16/09..\$15.00

DOI: http://dx.doi.org/10.1145/2968219.2972717

\begin{abstract}
The field of $\mathrm{HCI}$ is changing, which brings with it new responsibilities. Ubiquitous computing touches on many aspects of modern life and its consequences are not yet fully understood. In the context of dementia ubiquitous technologies are currently developed to augment care and thereby enhancing quality of life for people living with dementia as well as reducing the financial pressures on the health care system. Within this paper a design fiction is presented as a method to explore the issues that may arise from the new technologies in this context. It introduces the idea of replacing Smart Home technology with wearable solutions to observe the technologies more critically through defamiliarization and use these observations to feed back into technology design.
\end{abstract}

\section{Author Keywords}

Dementia; Internet of Things; Smart Technologies; Design Fiction

\section{ACM Classification Keywords}

H.5.m. Information interfaces and presentation (e.g., $\mathrm{HCI}$ ): Miscellaneous 


\section{Introduction}

Ubiquitous devices have been proposed and are currently developed to support people living with dementia to maintain an independent lifestyle. Proposals have been made to support activities of daily living (e.g. [6]), enhance the safety of people living with dementia (e.g.[10]) and, to a lesser extent, create meaningful activities (e.g. [8]). A strong focus is on technologies embedded into the environment, particularly so called 'Smart Houses' [3]. Initial usability tests of these devices promise individual benefits, such as increased quality of life for people living with dementia [14], but also benefits to the health care system, such as cost reductions [12]. While none of the solutions are commercially available yet, experts in the field expect them to be available within the next decade [2]

The rise of ubiquitous computing technologies has led to changes in $\mathrm{HCI}$, which bring with them new responsibilities for researchers and developers in this field as for example Heidt, Bischof and Rosenthal [7] observe. According to DiSalvo [4] design practices will offer new impulses to respond to these new responsibilities. Considering the complexities of dementia care, this might have an impact on the usability and use of the technologies that are currently developed.

In regards to dementia autonomy may be undermined as technologies are becoming transparent to the user (see for example [11]). Studies such as the focus group study with formal and informal caregivers by Robinson et al. [13] show that the perceived need of some caregivers to keep people living with dementia safe is so strong that they are willing to overwrite the will of the person with dementia. This understanding is not yet integrated into technology, which currently leaves users potentially open to coercion or covert monitoring as technologies become transparent.

\section{SAFE suit}

Motivation

To better understand the complexities of the environment into which the ubiquitous technologies will be integrated, critical design methods are proposed. This paper is part of a wider PhD project that evaluates the use of critical design methods in the context of dementia. Methods such as design fiction enable a discourse on how these technologies would fit into their environment and context and use these reflection to iteratively enhance designs. Rather than contrasting positive and negative scenarios as proposed for example by Mancini et al. [9], the author specifically refers to the idea of speculative design as introduced by Dunne and Raby [5], which is not leading the viewer to judge the technology in one specific way, but rather to evaluate it more openly.

The 'SAFE suit' design fiction that is presented in this paper has been inspired by the literature on the topic and has been developed in two steps: I a first step the question "What if smart technologies were not connected to the house?" was used as a means of 'defamiliarization' [1]. In a second step the idea was written out as a narrative to explore how the technology might be used in a family context and what issues might arise from their everyday use.

The story described one specific case of coercion that had a potentially negative effect. Comparable to an 
observers use case it could be used to iteratively inform the design process.

\section{Design fiction}

My father is very, very stubborn. He has been for as long as I remember. But I have to admit, so am I. So we sometimes clash very strongly. All in all we go along well, but sometimes neither of us wants to budge. If anything, the dementia has made him even more stubborn. When he does not understand something, he does not want it. So when I brought in the idea of getting some gadgets to help him, he was dead against it. Shouted at me that he did not need them. I got him a sensor set for the house to try, but he just hid it away. Said he did not want to be monitored, no way. He just did not understand that I could not come and visit as often as I used to and what a problem it would cause if he fell.

So when I heard about the SAFE suit from a friend who had a similar problem I thought it was a godsend really. I only got the jacket which is really comfortable and has a lot of sensors built in. If you know what they are and where they are you can find them, but otherwise you really do not see them. They monitor position and behavior. When they detect something unusual, like him leaving the house late at night or him having a fall, it will connect wirelessly with his phone and sent out a notification to me. It has a microphone built in for emergencies, so when he shouts for help, but cannot reach the phone, it will give me a call. Theoretically you can listen in via the mic all the time to check if all is well, but I did not do this. I think he would not like that and I don't really need that. Maybe it would have been an option when things get harder, but not yet.
Well, I thought this sounded all great and I was happy to see Dad wearing the jacket. I was happy to know I'd get a text when something went wrong and he could just get on with his stuff. So, just imagine how shocked I was when he told me that he had given it to the cleaners a while ago. He said he spilled tea over it and got it cleaned. That's why I did not get any notifications. The thing was just not working anymore. I had no idea anything had happened. Dad did not tell me of course, because he had no idea what it meant. And I got so scared. What if something had happened? It feel it is quite dangerous, not letting people know that the suit is broken. And I know I want to be sure that he is safe. I will start the fight again about the house sensor. Until I win. My father is very, very stubborn. But so am I.

\section{Conclusion}

While new connected and context-aware technologies promise to be useful in the context of dementia, the consequences of their use are not yet sufficiently understood. The conflicts between different stakeholder views can lead to decreased autonomy of the person subjected to the technology in its current form. The pressure of formal and informal caregivers to keep the person with dementia safe, might lead to coercion into the use of these small or even transparent technologies.

By describing the use of potential designs in a family setting, those complexities come to the foreground and can be used to iteratively enhance the technologies. In the example presented in this paper, it has been avoided to present a completely positive or negative view on the technology, but rather to explore the relationship and possible outcomes in more depth. 
Borrowing from art and design, critical design methods can be one way of addressing interpersonal issues before technology implementation and let the results feed into the design process. It is proposed within this paper as one way to address the subtle responsibilities that arise within $\mathrm{HCI}$ as technologies change.

\section{Acknowledgements}

Thanks to my supervisor team for their support and the anonymous reviwers for their constructive feedback. This paper has been developed from a larger PhD project which is funded by the EPRSC.

\section{References}

1. Bell,G., Blythe, M., and Sengers, P. 2005. Making by Making Strange: Defamiliarisation and the Design of Domestic Technologies, ACM

Transactions on Computer-Human Interaction, Vol. 12(2), June 2005, 149-173

2. Boger,J. and Mihailidis, A. 2011. The Future of Intelligent Assistive Technology for Cognition: Devices Under Development to Support Independent Living and Ageing-with-Choice NeuroRehabilitation, 28, 271 - 280. DOI 10.1109/TITB.2005.864480

3. Bossen, A. et al. 2015. Emerging Roles for Telemedicine and Smart Technologies in Dementia Care Smart Homecare Technology and TeleHealth, 2015(3). 49 - 57. DOI: 10.2147/SHTT.S59500

4. DiSalvo, C. 2014. The GrowBot Garden Project as DIY Speculation Through Design, In: M. Ratto; M. Boler. (eds.) DIY Citizenship: Critical Making and Social Media. Cambridge: MIT Press, 237 - 247

5. Dunne, A. and Raby, F. 2013. Speculative Everything: Design, Fiction and Social Dreaming. Cambridge: MIT Press

6. Evans, N. Carey-Smith, B. Orpwood, R. 2011. Using Smart Technology in an Enabling Way: a
Review of Using Technology to Support Daily Life for a Tenant with Moderate Dementia British Journal of Occupational Therapy, 74(5), 249 - 253 DOI: $10.4276 / 030802211$ X13046730116614

7. Heidt, M. Bischof,A., and Rosenthal, P. 2014. Deconstructivist Design Within HCI A. Marcus (Ed.): DUXU 2014, Part I, LNCS 8517, 115-122

8. Lazar, A. 2014. Using Technology to Increase Meaningful Engagement in a Memory Care Unit. GROUP'14, November 9-12, 2014, Sanibel Island, Florida, USA, 255 - 257

9. Mancini, C. et al. 2010. Contravision: Exploring Users' Reactions to Futuristic Technology. Proceedings of the 28th International Conference on Human Factors in Computing Systems, 10-15 April 2010, Atlanta Georgia, USA, 153 - 162

10. McKenzie, B. et al. 2013. Safe Home Program: A Suite of Technologies to Support extended Home Care of Persons with dementia American Journal of Alzheimer's Disease \& Other Dementias, 28(4), 348 - 354. DOI: 10.1177/1533317513488917

11. Orpwood, R. et al. 2005. The design of Smart Homes for People With Dementia: User-Interface Aspects, Universal Access in the Information Society, 4, $156-164$

12. Pollack, M. 2005. Intelligent Technology for an Ageing Population: The Use of AI to Assist Elders with Cognitive Impairments AI Magazine, 26(2), 9 $-24$

13. Robinson, L. et al. 2007. Balancing Rights and Risks: Conflicting Perspectives in the Management of Wandering in Dementia Health, Risk and Society, 9(4), 389 - 406, DOI:

$10.1080 / 13698570701612774$

14. Sixsmith, A. et al. 2007. Developing a Technology 'Wish-List' to Enhance the Quality of Life of People with Dementia Gerontechnology, 2007, 6(1), 2 19. DOI 10.4017/gt.2007.06.01.002.00 